\title{
Specialized pollinators and seed production of Trollius species introduced in Western Siberia
}

\author{
Anastasiya Gusar ${ }^{1, *}$, and Lubov Buglova ${ }^{2}$ \\ ${ }^{1}$ FSEE HPE FSEI "Novosibirsk State Agrarian University", Russia \\ ${ }^{2}$ FSIS "Central Siberian botanical garden SB RAS", Russia
}

\begin{abstract}
In five species of Trollius L., seed production of fruits was studied, plants being grown in culture in the forest steppe zone in Western Siberia. 2 species representing Chiastocheta genus were identified as specialized pollinators (Diptera, Anthomyiidae). Those insects pollinate the flowers and damage the seeds of three globeflower species: T. apertus, $T$. europaeus $T$. asiaticus. The flower season of other two species ( $T$. chinensis and T. ledebourii) starts later and the plants can't be exposed to invasion, as Chiastocheta flies are at their larval stage yet. Pollination of these species is performed by non-specialized agents. The lowest rate of seed production realization of about $20 \%$ is registered in T. europaeus, while in $T$. ledebourii it is the highest comprising $71 \%$. We consider the flies of Chiastocheta genus as an important part of the complex of factors lowering seed productivity in Trollius and their relationship as parasitism. Thus, in West Siberia for Trollius seed production increase, measures intended to reduce Chiastocheta abundance will be useful.
\end{abstract}

\section{Introduction}

Trollius L. representatives growing in temperate latitudes are frost-resistant and promising for introduction in Siberian region. They possess valuable decorative and medicinal properties $[1,2]$. In $T$. chinensis, there have been extracted flavonoids exposing proved cancer-fighting activity [3].

Plants of Trollius genus being allogamous, pollination agents study turns to be a question of strategy for obtaining seeds. Flowering of introduced species shows its speciesspecific character in culture as well [4].

Specialized pollinators for Trollius genus the flies of Chiastocheta genus (Diptera, Anthomyiidae) are [5]. The influence of those agents is controversial. Chiastocheta imago individuals eat nectar of Trollius flowers and concurrently perform pollination gaining to production of seeds. On the other hand, larvae are parasites feeding on nothing but seeds and fruit tissues of Trollius genus plants. That decreases seed productivity [6, 7].

For T. europaeus L., Chiastocheta flies are described to be the only pollinator, as the closed globe-shaped flower makes getting in possible for small-sized insects exclusively. $T$.

\footnotetext{
*Corresponding author: gusara663@gmail.com
} 
europaeus and Chiastocheta have mutual evolution, so their relationship can be identified as obligate mutualism. However, for other Trollius species Trollius-Chiastocheta interaction is parasitism, since the plants can also be pollinated by non-specialized agents as bees and bumblebees. Thus, the importance of specialized agents for seed production in species with open flower turns less sufficient [8].

The study targets to identify Chiastocheta species and to assess seed production in their host-plants of Trollius genus from the collection of Central Siberian botanical garden SB RAS.

\section{Materials and Methods}

The collection ground of Central Siberian botanical garden is located in the south-east of the West Siberian Plain in the southern outskirts of Novosibirsk. The coordinates are N 54.82; E 83.10 by google/maps; h: 130m.a.s.l. seed production in five species was assessed in 2017.

Chiastocheta species were identified in the generally recognized way according to the key reference-books $[9,10]$ by male genitals morphology (surstyli, cerci and V sternite projections) and by comparison with the identified species of St. Petersburg outskirts from the collection of Zoology Institute RAS.

Chiastocheta eggs and larvae along with Trollius seed production were calculated per fruit comprising a number of uncombed follicles (Table 1, 2). Seed productivity was studied according to the technique proposed by I.V.Vaynaghy [11] and being modified for aggregate follicles of Trollius. The percentage of seeds eaten by larvae was calculated from the total number of the developed ones. Potential seed productivity was assessed with a SteREO Discovery V12 stereomicroscope photos taken by AxioCam MRc-5 camera.

\section{Results}

For all the Trollius species, we have determined Diptera и Hymenoptera orders representatives as pollinators. In every T. Europaeus individual, sepals are not completely closed in the upper part, thus the flowers can be pollinated by non-specialized agents (Fig. $1)$.

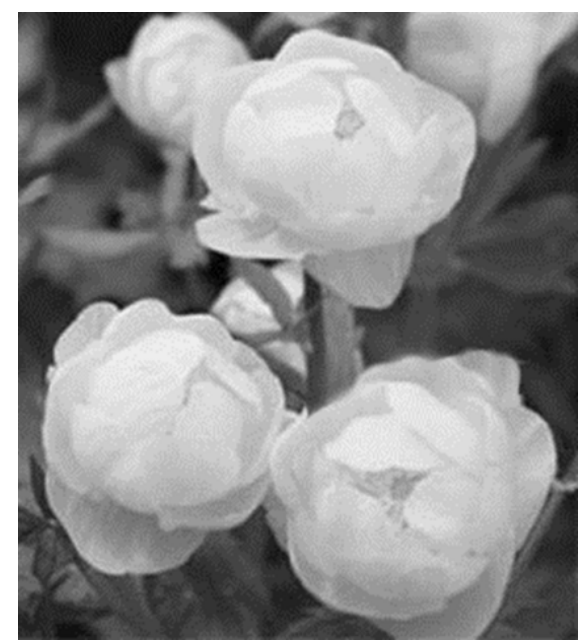

Fig. 1. T. europaeus in USU № 440534 collection. 
In T. apertus and T. europaeus, the terms of flowering are very similar, being mainly overlapped by flowering of the aboriginal $T$. asiaticus species. For them, two specialized pollinator species have been revealed: Ch. trollii and Ch. sp. (rotundiventris); both got acclimatized to the introduced successfully.

In $T$. chinensis and T. ledebourii the flowering starts about three weeks later than in $T$. asiaticus. During this period, all the specialized flies are passing the larvae stage; that is why summer-blossoming species can't de invaded. Larvae emergence from eggs occurs on the $2-4^{\text {th }}$ day after the flowering period of the vulnerable species is over.

Table 1. Eggs and larvae number on Trollius fruits.

\begin{tabular}{|l|c|c|c|c|c|c|}
\hline \multirow{2}{*}{$\begin{array}{l}\text { Number } \\
\text { Species }\end{array}$} & \multicolumn{2}{|c|}{$\mathrm{N}$} & \multicolumn{2}{c|}{ Eggs } & \multicolumn{2}{c|}{ Larvae } \\
\cline { 2 - 7 } & total & $\begin{array}{l}\text { Without } \\
\text { larvae }\end{array}$ & maximum & average & maximum & average \\
\hline T. asiaticus & 6 & 1 & 8 & 2.83 & 6 & 2 \\
\hline T. europaeus & 14 & 4 & 6 & 1.53 & 3 & 0,67 \\
\hline
\end{tabular}

Number of eggs blown by Chiastocheta flies onto the host plant follicules can vary a lot (Table 1). The most active blowing is observed on T. apertus plants. There may be up to 8 eggs per fruit. Correspondingly, up to 6 larvae may be feeding on one fruit. However, in all the species, some fruits have been detected without any eggs or larvae. The largest number of totally larvae-free fruits is registered in T. asiaticus, thus providing a lower average rate of invasion. The average invasion rate in fruits of the aboriginal species turns to be more than three times lower, in comparison to the one in the introduced T. apertus и $T$. europaeus.

Table 2. Seed production of the globeflower introduced species.

\begin{tabular}{|c|c|c|c|c|c|}
\hline to & Follicle, & Fruit (agg & gate follicle) & Developed & Eaten \\
\hline compare & $\begin{array}{l}\text { actual } \\
\text { average } \\
\text { number of } \\
\text { seeds }\end{array}$ & $\begin{array}{l}\text { Actual } \\
\text { average } \\
\text { number of } \\
\text { seeds }\end{array}$ & $\begin{array}{l}\text { Potential } \\
\text { average } \\
\text { number of } \\
\text { seeds }\end{array}$ & seeds, $\%$ & $\begin{array}{l}\text { seeds, } \\
\%\end{array}$ \\
\hline T. apertus & $10.23 \pm 0.24$ & $63.67 \pm 18.22$ & $226.03 \pm 39.98$ & 28.38 & 19.62 \\
\hline T. asiaticus & $9.90 \pm 0.29$ & $66.67 \pm 8.31$ & $224.88 \pm 16.88$ & 30.23 & 17.93 \\
\hline T. europaeus & $7.83 \pm 0.60$ & $47.70 \pm 8.94$ & $231.97 \pm 21.62$ & 20.48 & 17.56 \\
\hline T. chinensis & $13.10 \pm 0.16$ & $94.06 \pm 7.60$ & $316.48 \pm 12.96$ & 32.31 & - \\
\hline T.ledebourii & $11.14 \pm 0.21$ & $216.09 \pm 17.93$ & $324.62 \pm 17.41$ & 71.48 & - \\
\hline
\end{tabular}

The potential seed production of fruits is higher in the species not exposed to Chiastocheta invasion than in the vulnerable ones (Table 2). The actual seed production appears to be the highest in T. ledebourii, while the lowest - in T. europaeus up to complete withering of fruits during their maturation period. However, no direct dependence of productivity on the invasion rate is revealed. In T. ledebourii, the actual seed production is more than twice as high as in T. chinensis. Similar tendency is observed in the vulnerable species. All the three species involved have nearly equal potential production, while the actual seed production is the lowest in T. europaeus, despite the flyblown of T. europaeus and T. asiaticus plants being close. 


\section{Discussion}

In the region under the study in West Siberia, we have detected 2 species of specialized pollinators Ch. trollii and Ch. sp. (rotundiventris), which are found in Europe as well [8]. Their behavior corresponds to the data of literature [12].

The tendency of the introduced T. apertus and T. europaeus species to higher invasion rate can most probably be explained by the peculiarities of Trollius-Chiastocheta consortium mutual evolution in each region, thus the aboriginal species $T$. asiaticus turns to be a little more resistant to the invasion by flies. This confirms the reports on plants ability to increase the content of Chiastocheta-protective compounds [13, 14].

Aside from the pollination agent's blown, seed production decrease in T. europaeus can additionally be caused by the introduction of plants to more severe climatic conditions.

Introduction effectiveness is determined by the plant ability to reproduction [15], so in West Siberia, T. ledebourii proved to be the most successful and productive, as here this species is affected by two more beneficial factors (rhythm and climate) than within its natural habitat. Both factors provide them the invulnerability to Chiastocheta larvae invasion. Pollination by non-specialized agents turns to be enough for Trollius species mass seed production when grown in culture under conditions of West Siberia.

In this connection, Trollius-Chiastocheta relationship should be considered as the form of parasitism even for T. europaeus. For Trollius species cultivation, measures intended to reduce Chiastocheta abundance are desired to increase plant seed production.

Authors are grateful to E.P. Narchuk for identified insects being put at our disposal to confirm the identification of Chiastocheta species under the study.

\section{References}

1. N. V. Shipchinsky. Flora of the USSR 7 (Moscow, 1937) In Russ.

2. M. N. Povydysh, N. V. Petrovva, N. I. Medvedeva Wild flowering plants, their component composition and biological activity 1, 24-66 (2008) In Russ.

3. S. Wang, Q. Tian., F. An, Oncology Letters 12, 1705-1710 (2016)

4. L. V. Buglova, Vestnik IrGSCHA 44, 35-41 (2011) In Russ.

5. V. Michelsen, A revision of the Anthomyiidae (Diptera) described by J. W. Zetterstedt, Steenstrupia.37-65 (1985)

6. N. Jaeger, L. Despres, C. R. Acad. Sci. Paris 321, 789-796 (1998)

7. L. Despres, N. Jaeger. J .of Evol. Biol. 12, 822-831 (1999)

8. O. Pellmyr, Biol. J. of the Linn. Soc. 47, 337-365 (1992).

9. W. Henning, Beitr. Entomol. 3, 655-668 (1953)

10. J. E. Collin, Proc. R. Entomol. Soc. 23:95-102 (1954)

11. I. V. Vaijganii, Bot. J.59, 826-830 (1974)

12. F. Pompanon, E. Pettex, L. Després, Acta Oecologica 29, 233-240 (2006)

13. C. Gallet, S. Ibanez, L. Zinger, J. Chem. Ecol. 33, 2078-2089 (2007)

14. S. Ibanez, C. Gallet, F. Dommanget, BMC Evol. Biol. 9, 261 (2009)

15. R. A. Kapisonova. Herbaceous plants of the USSR broad-leaved forests: ecologofloristic and introduction characteristics (Nauka, Moscow, 1985) In Russ. 